\title{
AN EXPERIMENTAL AND NUMERICAL STUDY OF SUPERCAVITATING FLOWS AROUND AXISYMMETRIC CAVITATORS
}

\author{
S. Morteza Javadpour, Said Farahat \\ University of Sistan and Baluchestan, Department of Mechanical Engineering, Zahedan, Iran \\ e-mail: javadpour_m@yahoo.com; farahat@hamoon.usb.ac.ir
}

HOSSEIN AJAM

Ferdowsi University of Mashhad, Department of Mechanical Engineering, Mashhad, Iran; e-mail: h.ajam@um.ac.ir

MaHmoud SALARI

Imam Hossein University, Department of Mechanical Engineering, Tehran, Iran; e-mail: msalari@ihu.ac.ir

Alireza Hossein NeZHad

University of Sistan and Baluchestan, Department of Mechanical Engineering, Zahedan, Iran

e-mail:nezhadd@hamoon.usb.ac.ir

\begin{abstract}
It has been shown that developing a supercavitating flow around under-water projectiles has a significant effect on their drag reduction. As such, it has been a subject of growing attention in the recent decades. In this paper, a numerical and experimental study of supercavitating flows around axisymmetric cavitators is presented. The experiments are conducted in a semi-open loop water tunnel. According to the Reynolds-Averaged Navier-Stokes equations and mass transfer model, a three-component cavitation model is proposed to simulate the cavitating flow. The corresponding governing equations are solved using the finite element method and the mixture Rayleigh-Plesset model. The main objective of this research is to study the effects of some important parameters of these flows such as the cavitation number, Reynolds number and conic angle of the cavitators on the drag coefficient as well as the dimensions of cavities developed around the submerged bodies. A comparison of the numerical and experimental results shows that the numerical method is able to predict accurately the shape parameters of the natural cavitation phenomena such as cavity length, cavity diameter and cavity shape. The results also indicate that the cavitation number declines from 0.32 to 0.25 leading to a 28 percent decrease in the drag coefficient for a $30^{\circ}$ cone cavitator. By increasing the Reynolds number, the cavity length is extended up to $322 \%$ for a $60^{\circ}$ cone cavitator.
\end{abstract}

Keywords: natural cavitation, mass transfer, water tunnel, finite element method, drag coefficient, axisymmetric cavitators

\section{Introduction}

Cavitation is the formation of vapor bubbles within a liquid when the liquid pressure falls less than the saturated vapor pressure while the fluid temperature remains lower than the boiling temperature at ambient conditions. Cavitation phenomena are observed in many hydrodynamic mechanical devices such as pumps, turbines, nozzles and marine propellers, which can significantly influence the performance of these devices. Cavitation may cause negative effects like structural damages, noise production and power losses in plants, or generates positive effects such as drag reduction of underwater moving bodies. However, for military purposes such as torpedoes, it is necessary to generate partially- or fully super-cavitating regime to reduce viscous drag intentionally.

The cavitation phenomenon is divided into three stages. The initial form of cavitation is the bubble stage which has destructive impacts on mechanical systems. Partial cavitation is another 
stage in which the cavity region covers some parts of the body. The last stage is supercavitation in which size of the produced cavity exceeds the characteristic length of the body. When supercavitation occurs, the drag of the bodies surrounded by the cavity is reduced significantly. This is due to reduction in the skin friction drag which depends on viscosity of the near-wall fluid flow, where the vaporous pocket of supercavity surrounds the moving underwater body. Supercavitation can also be divided into natural and ventilated cases. The natural supercavitation occurs when free stream velocity rises above a certain limit $(U>45 \mathrm{~m} / \mathrm{s}$ at sea level, which increases with submersion depth, or $p_{\infty}$ of the body. This phenomenon can also be achieved by decreasing the ambient pressure $p_{\infty}$, which is only feasible in cavitation tunnels.

The static hydrodynamic forces and the cavity shape associated with cavitators were modeled by many researchers in the last decades (Logvinovich, 1969, 1980; Kuklinski et al., 2001; Vasin and Paryshev, 2001; Wang et al., 2005; Chen et al., 2006; Chen and Lu, 2008; Deng et al., 2004).

In the recent years, most of the studies related to supercavitating flows have been carried out numerically. Choi and Ruzzene (2006) explained stability conditions of a supercavitating vehicle using the finite element method (FEM). Hu and Gao (2010) used the cavitation model of Fluent software to simulate two-phase cavitating flows that contain water and vapor on axisymmetric bodies with disk cavitators. They showed that the vapor volume fraction and threshold phase-change pressure within the cavity under the same cavitation number gradually ascends as the Reynolds number increases. Huang et al. (2010) predicted the effects of cavitation over a NACA66 hydrofoil. They combined state equations of the cavitation model with a linear viscous turbulent method of mixed fluids in the Fluent software to simulate a steady cavitating flow. Since most cavitating flows are implemented at high Reynolds numbers and under unsteady conditions, a suitable turbulence model is required to provide an accurate estimate of cavitation. A variety of approaches, such as standard or modified two-equation turbulence models $(k-\varepsilon, k-\omega)$, have been used to investigate the effects of turbulence on cavitating flows (Wu et al., 2005; Liu et al., 2009, Huang and Wang, 2011; Phoemsapthawee et al., 2012). Large eddy simulation (LES) is another approach used in numerical cavitation modeling recently (Wang and Ostoja-Starzewski, 2007; Huuva, 2008; Liu et al., 2010; Lu et al., 2010). Nouri et al. (2008) used a modified version of the $k-\varepsilon$ turbulence model to simulate unsteady behavior of the cavity shedding and the re-entrant flow field. Park and Rhee (2012) studied the standard $k-\varepsilon$ and realizable $k-\varepsilon$ turbulence models by selecting Singhal's cavitation model at a cavitation number of 0.3 . They observed that the standard $k-\varepsilon$ model was more efficient in capturing the re-entrant jet than the realizable $k-\varepsilon$ model.

In the past decade, several researchers have experimentally investigated supercavitating flows around the bodies. Most of these studies focused on the shape of generated cavitation, velocity and pressure distributions of the flow field as well as control and stability of supercavitating vehicles. Lindau et al. (2002) studied a supercavitating flow around a flat disk cavitator. Beside general cavitating flows, many studies on supercavitating flows have been undertaken using experimental and numerical methods. Experimental methods mainly rely on pressure measurements and image processing technology. Lee et al. (2008) studied ventilated supercavitation for a vehicle pitching up and down in the supercavity closed region. Hrubes (2001) studied a supercavitating flow in underwater projectiles using image production and processing to examine flight behavior, stability mechanism, cavity shape and in-barrel launch characteristics. Recently, Li et al. (2008) studied the cavitating flow by the flow visualization technique using a high-speed camera. They also measured details of the velocity field by the particle image velocimetry (PIV) to validate the computational models. The shape properties of natural and ventilated supercavitation on a series of projectile were investigated experimentally by Zhang et al. (2007). Wu and Chahine (2007) studied supercavitation on the back of a simulated projectile and measured the properties of the fluid inside the supercavity. Hua et al. (2004) conducted an experimental study on a cavitation tunnel with four axisymmetric bodies at different attack angles. Feng et 
al. (2002) studied behavior of a supercavitating and cavitating flow around a conical body of evolution with and without ventilation at several attack angles. Zhang et al. (2007) performed a series of projectile and closed-loop water-tunnel experiments to study shape properties of natural and ventilated supercavitation. Saranjam (2013) did an experimental and numerical study of cavitation on an underwater moving object based on unsteady effects and dynamic behavior of the body.

Most experimental studies on supercavitation have been performed in a closed-loop water tunnel with only a few investigations examining the supercavitation flow in an open circuit water tunnel. Also, many experimental studies have been performed to obtain detailed information on the cavity shape (Fang et al., 2002; Saranjam, 2013, Ji and Luo, 2010; Ahn et al., 2010; Zou et al., 2010). In this study, important supercavitation parameters including the shape of cavity, formation and the drag coefficient of the cavitator are investigated experimentally in a semi-open water tunnel complemented by a numerical analysis with the CFX software.

The paper is organized as follows: first a description of the physical problem followed by an experimental and numerical analysis is presented. Then, the experimental and computational results are presented and discussed. Finally, a summary of the results is given and the related conclusions are drawn.

\section{Exprimental set-up}

The experiments were conducted in a water tunnel located at the Marine Research Center of Iran. The tunnel is a semi-open loop water tunnel with a maximum velocity of $40 \mathrm{~m} / \mathrm{s}$. The water tunnel is equipped with a computerized control system, a high frequency data acquisitioning system, DAS, and a high-speed camera. A schematic view of the components of the water tunnel is shown in Fig. 1. The body of the model includes cone and cylindrical parts.

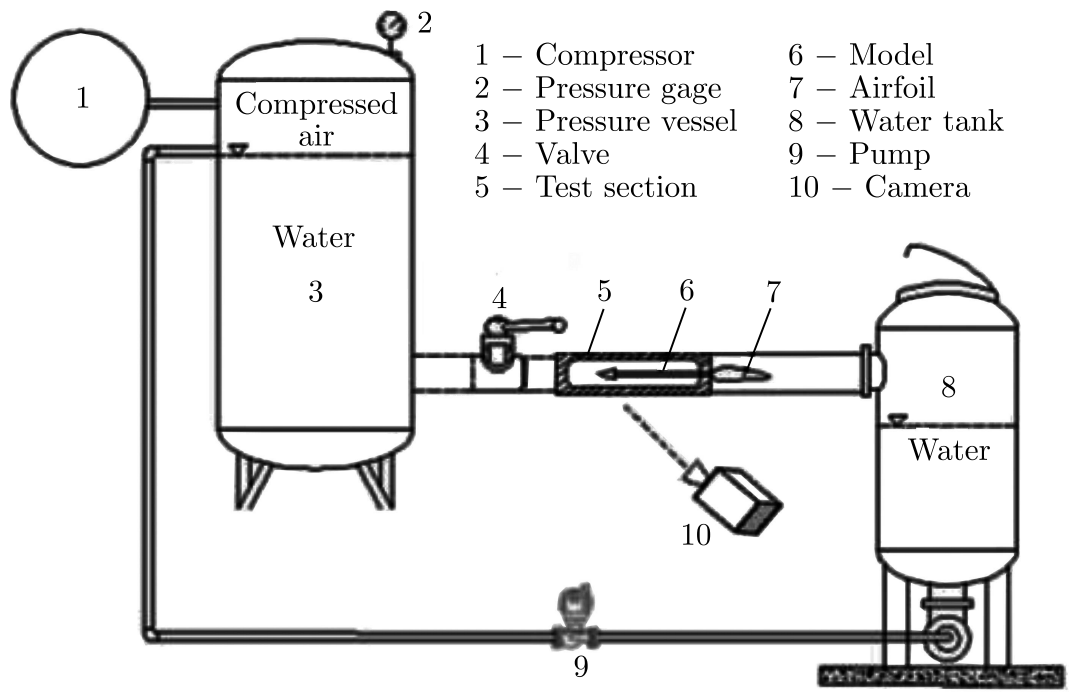

Fig. 1. A schematic view of the water tunnel. The figure is not to scale

The cavitating flow generated around the symmetric cone was investigated based on the experimental observations carried out in a water tunnel. Figure 2 a shows the test section, where the cone cavitator is also placed. The test section has a cylindrical form with diameter of $D$ and a length of $5 D$ (Fig. 2b). The side walls of the test section are made of plexiglas with a highly smoothed surface. At the outlet of the test section, atmospheric pressure conditions occur and the fluid flow is discharged into an open surface storage tank. This water tunnel also includes a vertical cylindrical tank as the main water tank which is initially filled with pure water up 
to a certain level and then the remaining volume is charged with pressurized air. Depending on the requested speed, the pressure of the air within the tank is varied. The model is attached to an electronically-load cell mounted outside the test section. The model with the cone cavitator is shown in Fig. 3. The base diameter of the cone cavitator is $10 \mathrm{~mm}$ and the cone angles for the noses are $30^{\circ}, 45^{\circ}$ and $60^{\circ}$. The cone length of $y_{0}$ is calculated according to the cone angle. The Reynolds number (Re) based on the diameter of the test section changes from 1120000 to 1480000 relative to the stream velocity within the test section.

(a)

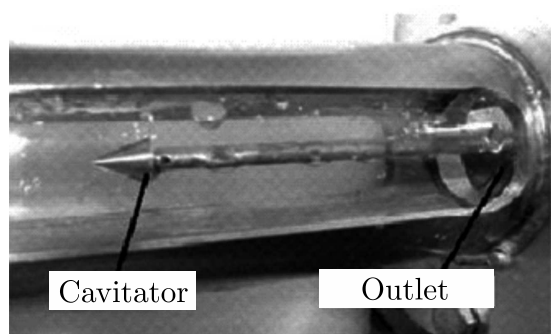

(b)

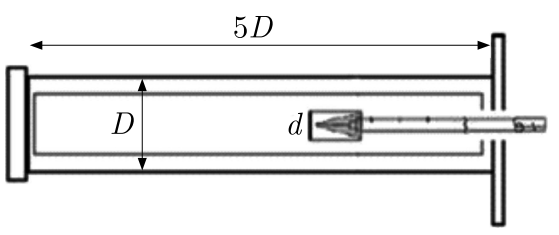

Fig. 2. (a) Test section of the water tunnel. (b) Dimensions of the test section

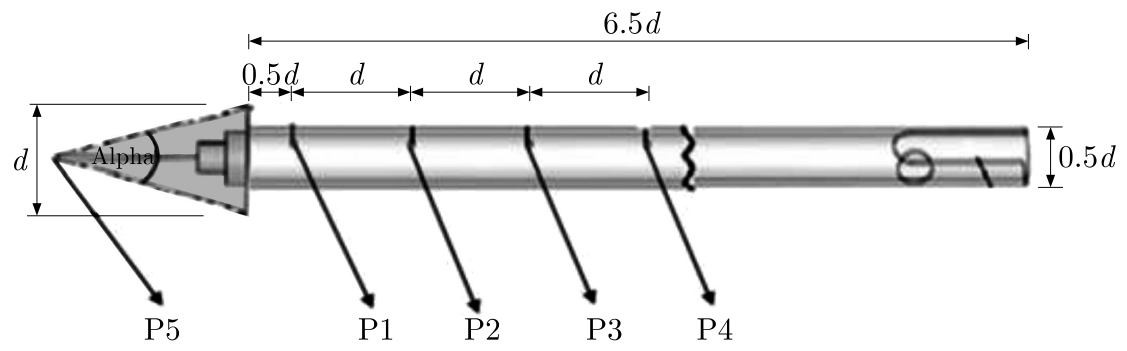

Fig. 3. A schematic view of the model and the position of pressure measurement cavities

The water tunnel was also equipped with some electronic pressure sensors to measure pressures in the flow. Five pressure sensors were used to gauge the pressure on the surface of the cylindrical part of the model (Fig. 3) behind the cone cavitator. Two pressure sensors were also placed inside the test section (P6) and the water tank (P7). The accuracy of sensors was \pm 0.01 bar. The output analog signals of the sensors were converted into digital signals via an A/D card, and the digital results were finally recorded online. It should be noted that the frequency of data recording was $1000 \mathrm{~Hz}$ for all of the sensors in the experiments. The cavitation profile formed around the cavitator was captured by a high-speed camera with a frame rate of 600 fps.

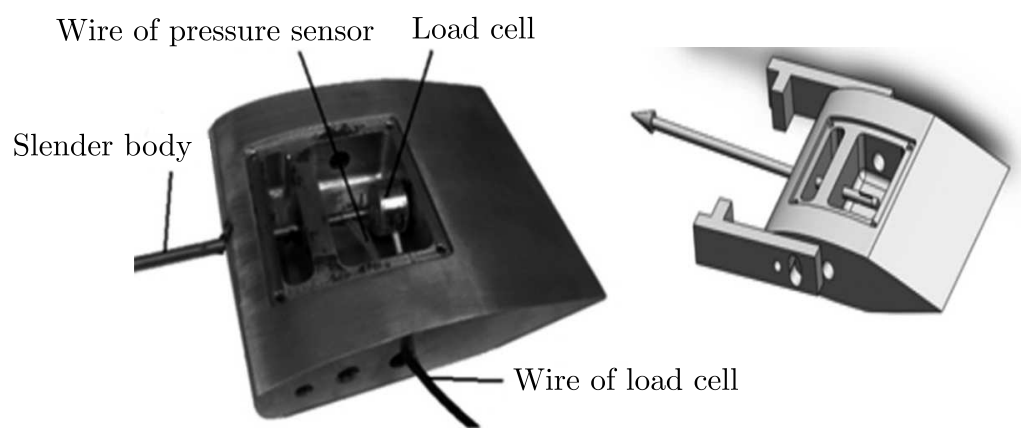

Fig. 4. Load cell mounted within the airfoil

To measure the drag force, an electronically-load cell of $49 \mathrm{~N}$ was mounted within a standard airfoil at the outlet of the test section (Fig. 4). Also, as shown in Fig. 4, the connecting wires of 
the load cell and the pressure sensor were driven out of the water tunnel test section via that airfoil.

To validate the experimental results of this study, the results of the cavitating flow around a flat disk were compared with the results of Franc and Michel (2004). In Fig. 5, the results of the present study for dimensionless cavity length $(\mathrm{Lc} / \mathrm{d})$ with respect to the cavitation number of the flow are compared with the experimental data of Franc and Michel. As can be seen, the results are in good agreement with their experimental data.According to Eq. (2.1), the theoretical value of the blockage cavitation number is about 0.211 , whereas the minimum value of the cavitation number at the maximum velocity of the present tests is about 0.25 . Since $\sigma_{\text {blockage }}<0.25$, the effect of blockage on the measured drag coefficient and cavity shape is expected to be negligible

$$
\sigma_{\text {blockage }}=\frac{S_{u}^{2}}{S_{d}^{2}}-1
$$

where $S_{u}$ and $S_{d}$ are the cross-sectional areas of the upstream and downstream regions of the liquid flow, respectively.

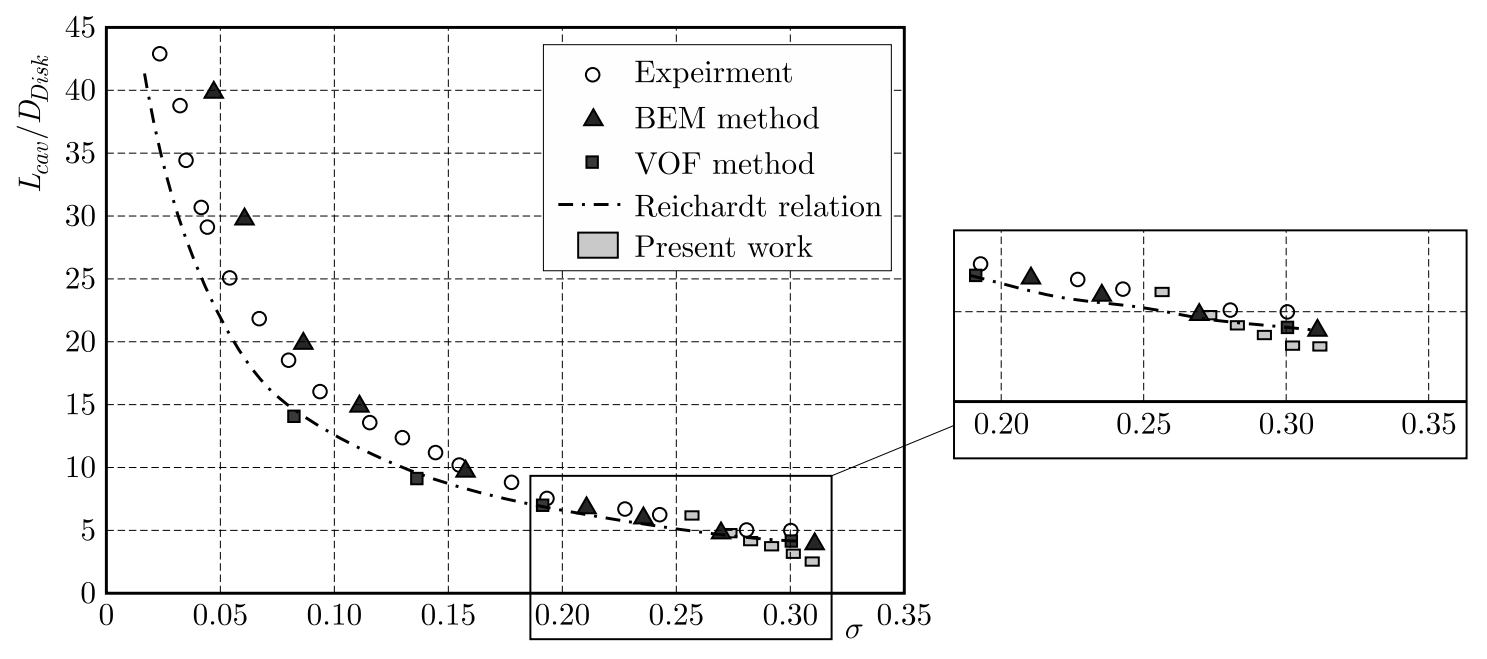

Fig. 5. Comparison of the present experimental results with the results of Franc and Michel (2004)

One of the fundamental dimensionless parameters for natural supercavities is the Froude number, $\mathrm{Fr}=U_{\infty} / \sqrt{g D}$. In these tests, the Froude number varies from 44.7 to 59 with the cavitation number ranging between 0.25 and 0.36. Semenenko (2001), citing Logvinovitch (1973), states that the effect of gravity can be significant if $\sigma_{v} \mathrm{Fr}<2$. Thus, at the present application, there is no need to incorporate the gravity effects.

\section{Mathematical models}

\subsection{Governing equations}

In this study, a mixture-type multiphase-flow model based on the isotropic hypothesis for the fluid along with the Reynolds averaged Navier-Stokes (RANS) equations are employed. The mass and momentum conservation equations are solved numerically to obtain the velocity and pressure fields. The mass, momentum, and volume fraction equations can be written as 


$$
\begin{aligned}
& \frac{\partial \rho_{m}}{\partial t}+\frac{\partial}{\partial x_{i}}\left(\rho_{m} u_{i}\right)=0 \\
& \frac{\partial}{\partial t}\left(\rho_{m} u_{i}\right)+\frac{\partial}{\partial x_{j}}\left(\rho_{m} u_{i} u_{j}\right)=-\frac{\partial P}{\partial x_{i}}+\frac{\partial}{\partial x_{j}}\left[\mu_{m}\left(\frac{\partial u_{i}}{\partial x_{j}}+\frac{\partial u_{j}}{\partial x_{i}}\right)\right]+\frac{\partial}{\partial x_{j}}\left(\tau_{t i j}\right) \\
& \frac{\partial}{\partial t}\left(\rho_{v} \alpha_{v}\right)+\frac{\partial}{\partial x_{i}}\left(\rho_{v} \alpha_{v} u_{i}\right)=m^{-}-m^{+}
\end{aligned}
$$

where $\alpha_{v}$ is the vapor volume fraction, $\rho_{v}$ is vapor density, $\rho_{l}$ is liquid density and $m^{-}, m^{+}$are mass transfer rates related to evaporation and condensation in cavitation, respectively. The density and dynamic viscosity of the mixture is calculated as

$$
\rho_{m}=\alpha_{v} \rho_{v}+\left(1-\alpha_{v}\right) \rho_{l} \quad \mu_{m}=\alpha_{v} \mu_{v}+\left(1-\alpha_{v}\right) \mu_{l}
$$

The non-dimensional parameters of interest in this study, including the cavitation number, drag coefficient and the Reynolds number, are defined as

$$
\sigma_{v}=\frac{P-P_{v}}{\frac{1}{2} \rho_{l} U_{\infty}^{2}} \quad C_{d}=\frac{F_{d}}{\frac{1}{2} \rho_{l} U_{\infty}^{2} A} \quad \operatorname{Re}=\frac{\rho_{l} U_{\infty} D}{\mu_{l}}
$$

where $P_{v}, F_{d}$ and $A$ are the vapor pressure, drag force and area of test section, respectively.

\subsection{Turbulence model}

The Reynolds stress can be modeled through the Boussinesq hypothesis according to the following equation

$$
\tau_{t i j}=\mu_{t}\left(\frac{\partial u_{i}}{\partial x_{j}}+\frac{\partial u_{j}}{\partial x_{i}}\right)-\frac{2}{3}\left(\rho k+\mu_{t} \frac{\partial u_{k}}{\partial x_{k}}\right) \delta_{i j}
$$

The standard $k-\varepsilon$ turbulence model,which is based on the Boussinesq hypothesis with transport equations for the turbulent kinetic energy $k$ and its dissipation rate $\varepsilon$ is adopted for the turbulence closure. The turbulent viscosity $\mu_{t}$, is computed by combining $k$ and $\varepsilon$ as $\mu_{t}=\left(\rho_{m} C_{\mu} k^{2}\right) / \varepsilon$, and the turbulence kinetic energy and its rate of dissipation are obtained from the transport equations as follows

$$
\begin{aligned}
& \frac{\partial\left(\rho_{m} k\right)}{\partial t}+\frac{\partial\left(\rho_{m} u_{j} k\right)}{\partial x_{j}}=\frac{\partial}{\partial x_{j}}\left[\left(\mu+\frac{\mu_{t}}{\sigma_{k}}\right) \frac{\partial k}{\partial x_{j}}\right]+G_{k}+G_{b}-\rho \varepsilon-Y_{M} \\
& \frac{\partial\left(\rho_{m} \varepsilon\right)}{\partial t}+\frac{\partial\left(\rho_{m} u_{j}\right)}{\partial x_{j}}=\frac{\partial}{\partial x_{j}}\left[\left(\mu+\frac{\mu_{t}}{\sigma_{\varepsilon}}\right) \frac{\partial \varepsilon}{\partial x_{j}}\right]+C_{\varepsilon 1} \frac{\varepsilon}{k}\left(G_{k}+C_{3 \varepsilon} G_{b}\right)-C_{\varepsilon 2} \rho \frac{\varepsilon^{2}}{k}
\end{aligned}
$$

where $C_{\mu}$ is an empirical constant (0.09). Here, the model constants $C_{\varepsilon 1}, C_{\varepsilon 2}, \sigma_{k}$ and $\sigma_{\varepsilon}$ are 1.44, $1.92,1.0$ and 1.3, respectively. The turbulent viscosity is used to calculate the Reynolds stresses to close the momentum equations. To model the flow close to the wall, a scalable wall-function approach has been adopted. The finite volume method is employed to discretize the integraldifferential equations. The second-order upwind scheme is applied to discretize the turbulent transportation equations.

\subsection{Cavitation model}

To model the cavitating flows, the two phases of liquid and vapor as well as the phase transition mechanism between them need to be specified. In this study, a "two-phase mixture" approach is introduced by the local vapor volume, which has the spatial and temporal variation of the vapor function, as described by the transport equation together with the source terms for the mass transfer rate between the two phases. Numerical models of cavitation differ in terms of 
the mass transfer term $\dot{m}$. The most common semi analytical models are the Singhal cavitation model (2002), Merkle model (1998), Schnerr and Sauer model (2001) and Kunz model (1999). In the present study, the cavitation model developed by Singhal et al. (2002) is used. The source terms included in the transport equation define vapor generation (liquid evaporation) and vapor condensation respectively. The source terms are functions of local flow conditions (static pressure and velocity) and fluid properties (liquid and vapor phase densities, saturation pressure and liquid vapor surface tension). The source terms are derived from the RayleighPlesset equation, where high-order terms and viscosity terms can be found according to Singhal et al. (2002)

$$
\dot{m}^{-}=C_{\text {evap }} \frac{V_{c h}}{\sigma} \rho_{l} \rho_{v} \sqrt{\frac{2}{3} \frac{p_{v}-p}{\rho_{l}}} \frac{\rho_{l} \alpha_{l}}{\rho_{m}} \quad \dot{m}^{+}=C_{\text {cond }} \frac{V_{c h}}{\sigma} \rho_{l} \rho_{v} \sqrt{\frac{2}{3} \frac{p-p_{v}}{\rho_{l}}} \frac{\rho_{v}}{\rho_{m}}
$$

where $C_{\text {evap }}=0.02, C_{\text {cond }}=0.01$ and $V_{c h}=\sqrt{k}, p_{v}, \sigma$ and $k$ denote the saturated pressure of liquid, surface tension and turbulence energy, respectively.

\section{Numerical method}

Numerical simulation (Ansys CFX 14) can be used to detect cavitation in the cavitation flow around the cone cavitator. It is important to note that ANSYS CFX uses the CV-FEM (control volume-finite element) method, with the latter having superior performance with the hexahedral mesh than with the tetrahedral one, which tends to degrade the computing efficiency.

Given the application of the CV-FEM method in ANSYS CFX 14, the linearized momentum and mass equations are solved simultaneously with an algebraic multi-grid method based on the additive correction multi-grid strategy. The implementation of this strategy in ANSYS CFX has been found to offer a robust and efficient prediction of the cavitation in pumps (Athavale et al., 2002; Pouffary et al., 2003). The high resolution scheme is adopted in space discretization to solve the differential equation as it has the second-order space accuracy.

\section{Computational domain and boundary condition}

The domain of the problem and boundary conditions are shown in Fig. 6.

The boundary conditions in the water tunnel are as follows:

- At the inlet, the velocity components, volume fractions, turbulence intensity and the length scale are specified.

- At the outlet, the pressure, volume fractions, turbulence intensity and the length scale are specified.

- The wall of the water tunnel and cavitator is assumed to be in no slip conditions.

The computational domain is $33 d$ in length and $5 d$ in diameter. To show the grid independency of the results, grids similar to that of Fig. 7 are used. Then, length and diameter cavity fractions are calculated and plotted in Fig. 8 at four different nodes $(N=120000, N=340000$, $N=530000$ and $N=720000$ nodes). It is observed that changes between the last two grids are small, so the grid with $N=530000$ nodes is chosen for the present study.In the total domain, the structural grid with 530000 nodes is formed. Figure 9 shows a 2D view of the mesh near the cavitator. Since the interaction between the near-wall flow and cavity should be taken into consideration, the near-wall mesh of the test body is well refined to ensure non-dimensional normal distance from the wall. The value of $y^{+}$at the wall surface of the cavitator is smaller than 100 (Fig. 9). 


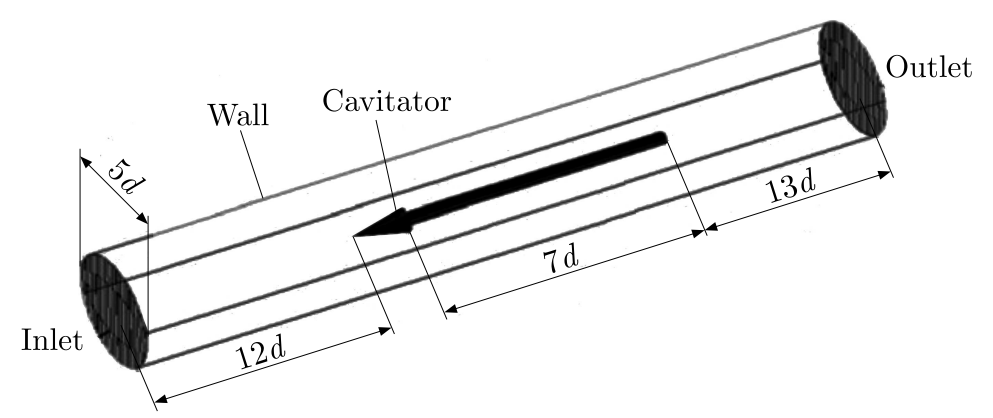

Fig. 6. Boundary condition and domain extent. The figure is not to scale

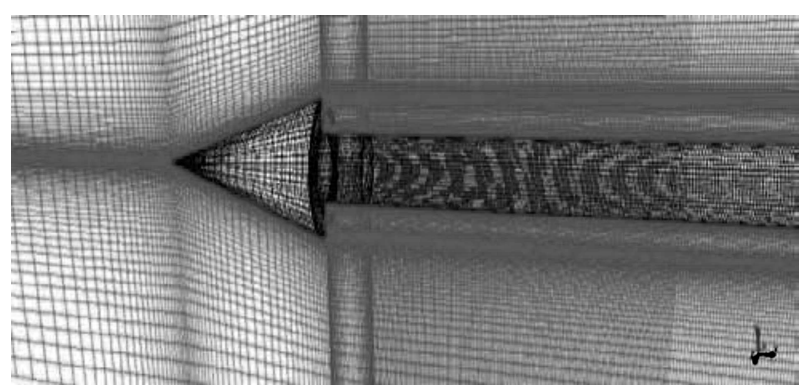

Fig. 7. The structure grid near the body

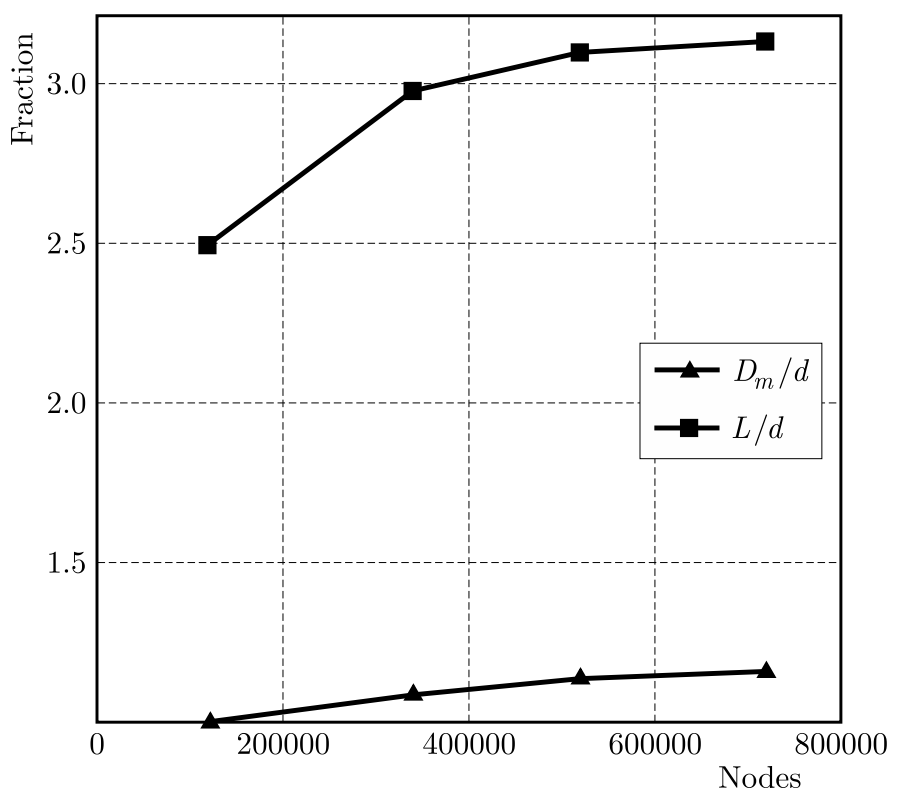

Fig. 8. Variations in length and diameter of cavity fractions at four different nodes

\section{Results and discussion}

\subsection{Drag coefficient}

In this Section, the drag force and drag coefficient are investigated for different cavitators. Figure 10 shows the drag force of the cavitator for $112 \cdot 10^{4}<\operatorname{Re}<148 \cdot 10^{4}$. It is observed that the drag force rises at a certain slope when velocity is increased. Generally, the drag is divided into pressure drag and viscous drag. The pressure remains constant in the cavity, but by decreasing the flow velocity, the pressure rises in the tip of the cavitator. Thus, as the flow velocity decreases, the friction drag drops and the pressure drag rises. This leads to overall 


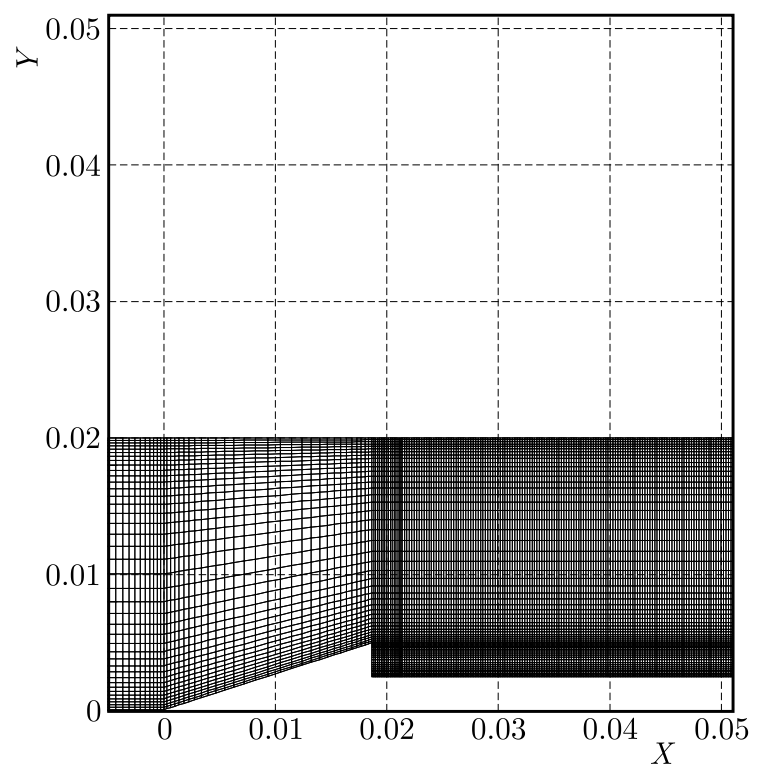

Fig. 9. Mesh near the cavitator

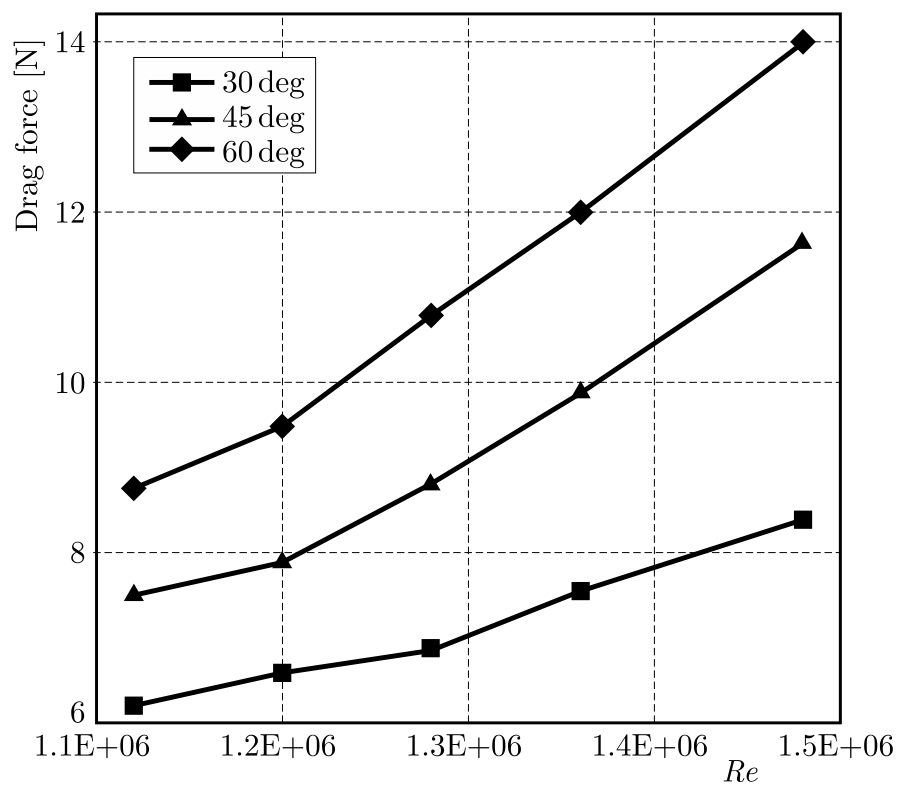

Fig. 10. Variation of the drag force found experimentally with the Reynolds number

reduction of the total drag. Finally, the drag coefficient goes up because variation in the square of velocity is greater than the total drag reduction (Eq. (3.3) 2 ).

Figures 11a and 11b indicate the experimental and numerical drag coefficients versus the cavitation and Reynolds numbers for various cavitator angles. A detailed comparison between the numerical results and available experimental data shows their good agreement for various angles of the cavitator. The results suggestthat the drag coefficient declines when the Reynolds number is increased. Figure 11b shows that at a constant Reynolds number, the drag coefficient increases proportionally to a rise in the cavitator angle. Equation $(3.3)_{1}$ illustrates the relation between flow velocity and the cavitation number. In the range of Reynolds numbers tested, the cavitation number variation is reduced with an increase in the cavitator angle (Fig. 11b). For $112 \cdot 10^{4}<$ Re $<148 \cdot 10^{4}$, by increasing the angle of the cavitator, changes in the cavitation number are lessened, and the slope of the drag coefficient versus the Reynolds number is reduced. In other 
words, by increasing the angle of the cavitator, similar changes occur in the square velocity and the drag force (Eq. (3.3) 2 ). Also, changes in the drag coefficient and cavitation number are similar for different cavitator types. For example, in a $60^{\circ}$ cone cavitator, the cavitation number variation is as small as the drag coefficient variations.

(a)

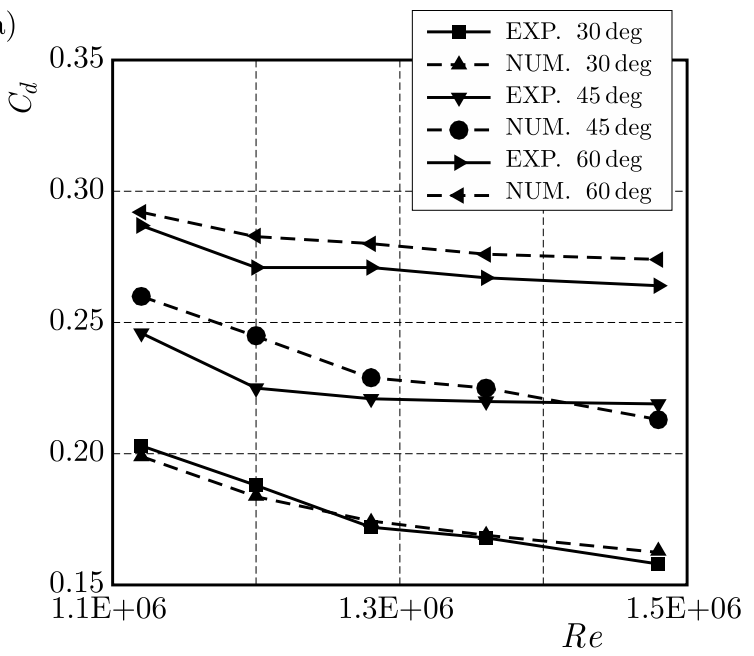

(b)

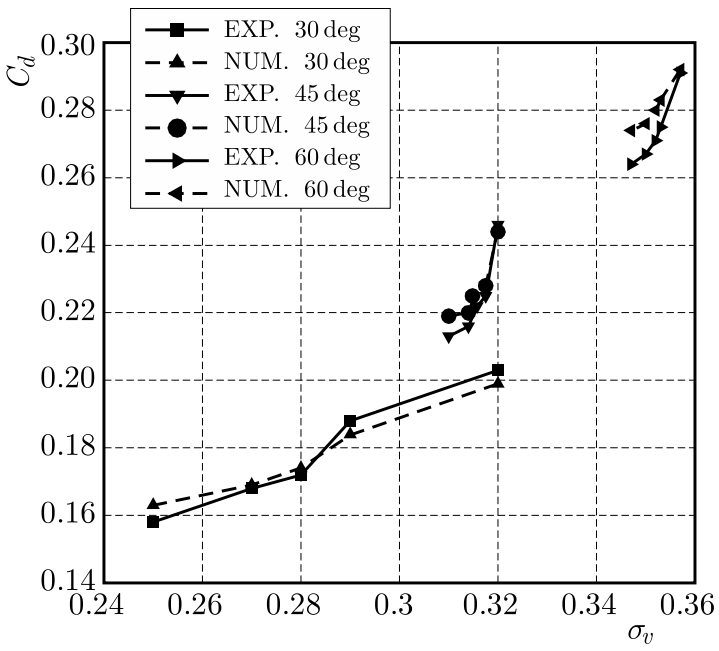

Fig. 11. Variation of the drag coefficient with the Reynolds number (a) and with the cavitation number (b)

\subsection{Cavity shape}

Figure 12 shows the effect of velocity variations on the cavity shape in the $30^{\circ}$ cone cavitator. The results indicate that the effect of velocity on the length of cavity is not significant. In Fig. 13, the shape of cavity for different cavitators at the velocity of $37 \mathrm{~m} / \mathrm{s}$ is displayed. The angle of the cavitator can affect the shape and type of cavitation.

Figure 16 shows contours of the volume fraction and streamlines around the $30^{\circ}$ cone cavitator. Figures 15 and 16 show contours of the pressure coefficient and turbulent eddy viscosity of the fully developed cavitating flow around the $45^{\circ}$ cone cavitator with the cavitation number of 0.33 . A comparison of Figs. 15 and 16 shows that the turbulent eddy viscosity is larger where the cavity is closed as a result of the re-entrant jet. Also, it is observed that the cavity pressure remains constant and where the cavity is closed, the pressure value peaks and then drops gradually. Thus, using this phenomenon, the length of cavity is estimated. For instance, when the flow velocity is $32 \mathrm{~m} / \mathrm{s}$, the cavity length of the $30^{\circ}$ cavitator will be $30.9 \mathrm{~mm}$ (Fig. 17).

The shape of the simulated cavity is compared with the one shown for the $30^{\circ}$ cone cavitator in Fig. 18. As can be seen, there is a good qualitative agreement between the experimental and numerical results obtained using CFX.

The experimental and numerical results indicate that with an increase in the Reynolds number, the maximum diameter of cavity rises to reach a nearly constant value. According to Fig. 19a, the relationship between flow velocity and natural cavitation numbers is weakened as the angle of the cavitator decreases. Moreover, the curve slope decreases as the Reynolds number rises. For lower angles, the results reveal that the maximum diameter of cavity remains constant as the cavitation number increases (Fig. 19b). For example, for $45^{\circ}$ and $60^{\circ}$ cavitators, the variation in the maximal diameter of cavity is negligible because the cavitation number variation is insignificant.

Figures 20a and 20b indicate the non-dimentionalized supercavity length for $30^{\circ}, 45^{\circ}$ and $60^{\circ}$ cone cavitators for which a comparison of the numerical and experimental results have been made. Figure 20a shows that the increased Reynolds number enlarges the cavity length at a 


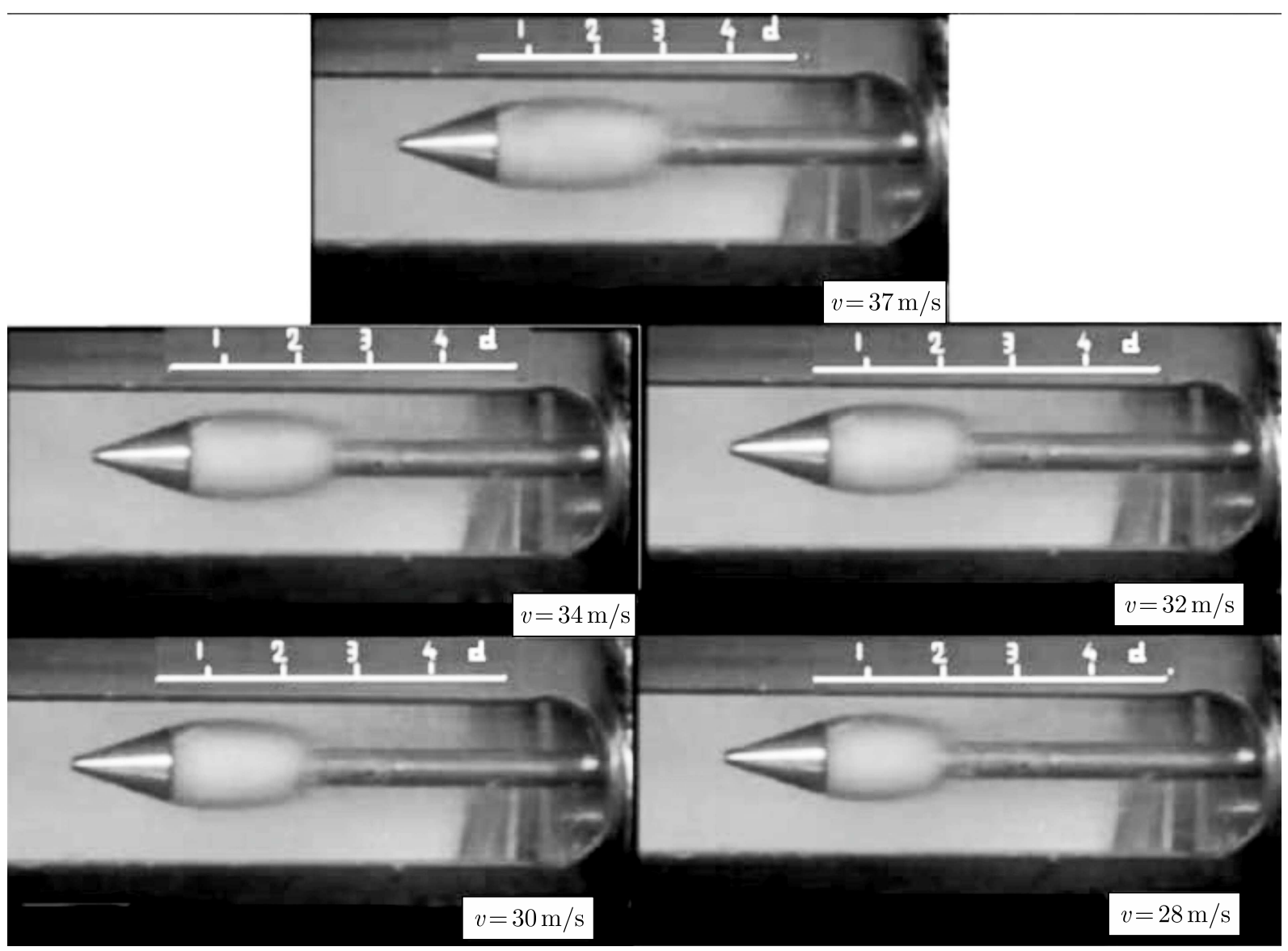

Fig. 12. Experimental results related to formation, evaporation, and condensation of supercavitation around the $30^{\circ}$ cone cavitator in the water tunnel under different velocities

(a)
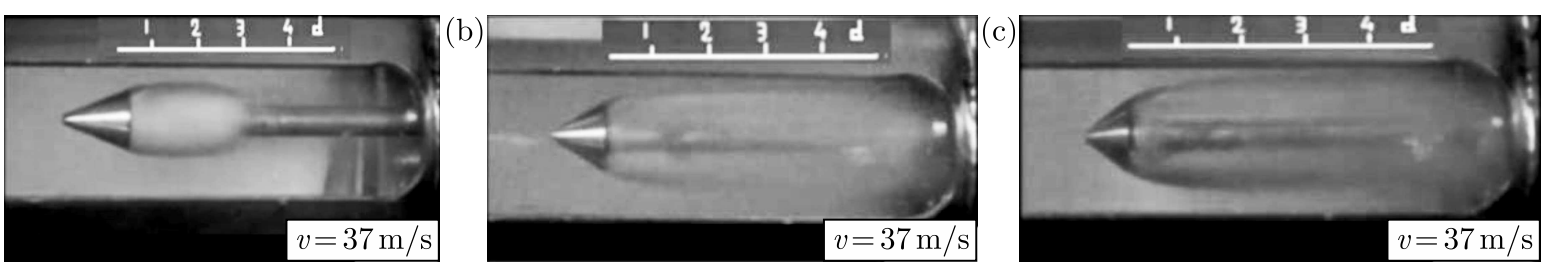

Fig. 13. Experimental results related to formation, evaporation and condensation cavity at different cavitators in the water tunnel at a velocity of $37 \mathrm{~m} / \mathrm{s}$; (a) $30^{\circ}$ cone cavitator, (b) $45^{\circ}$ cone cavitator,

(c) $60^{\circ}$ cone cavitator
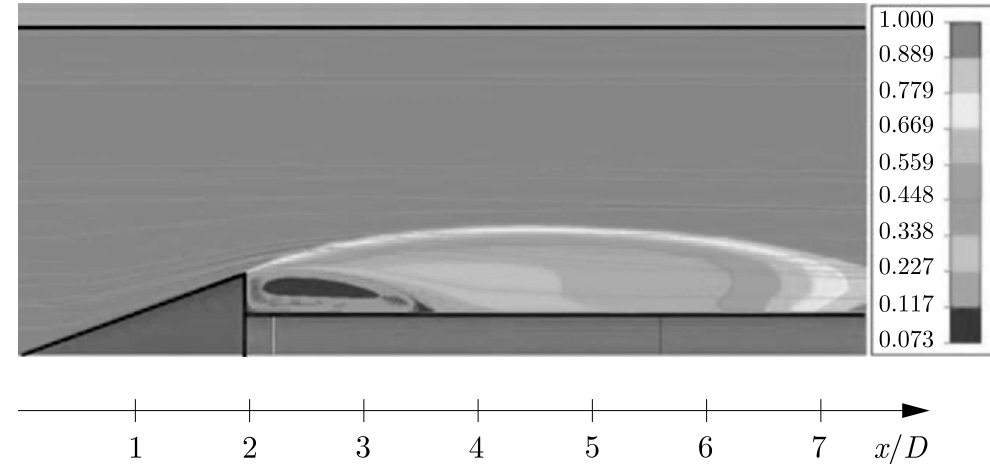

Fig. 14. Streamlines and water volume fraction contours around the $30^{\circ}$ cone cavitator at the velocity of $37 \mathrm{~m} / \mathrm{s}$ 


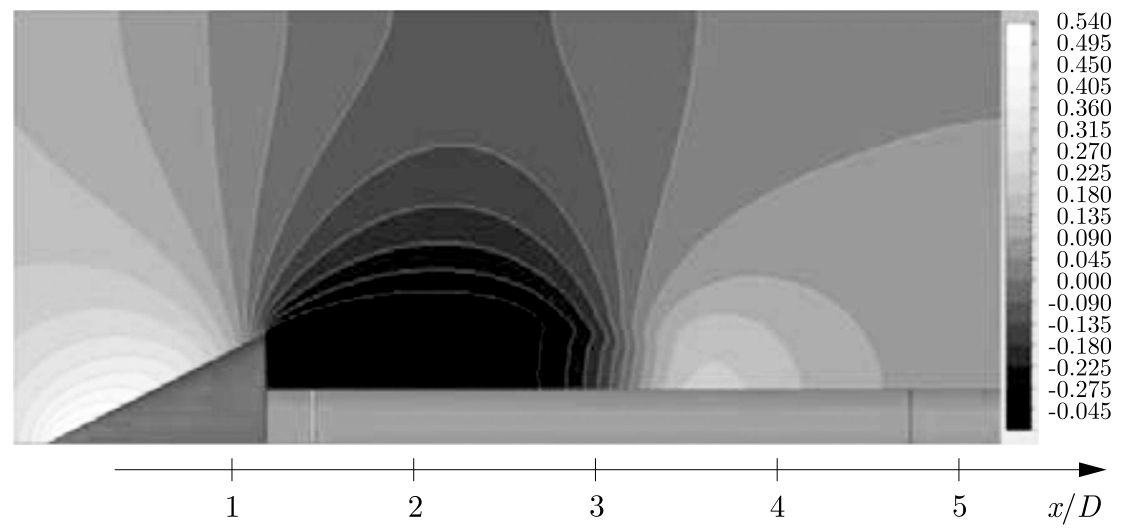

Fig. 15. Pressure coefficient contours around the $45^{\circ}$ cone cavitator

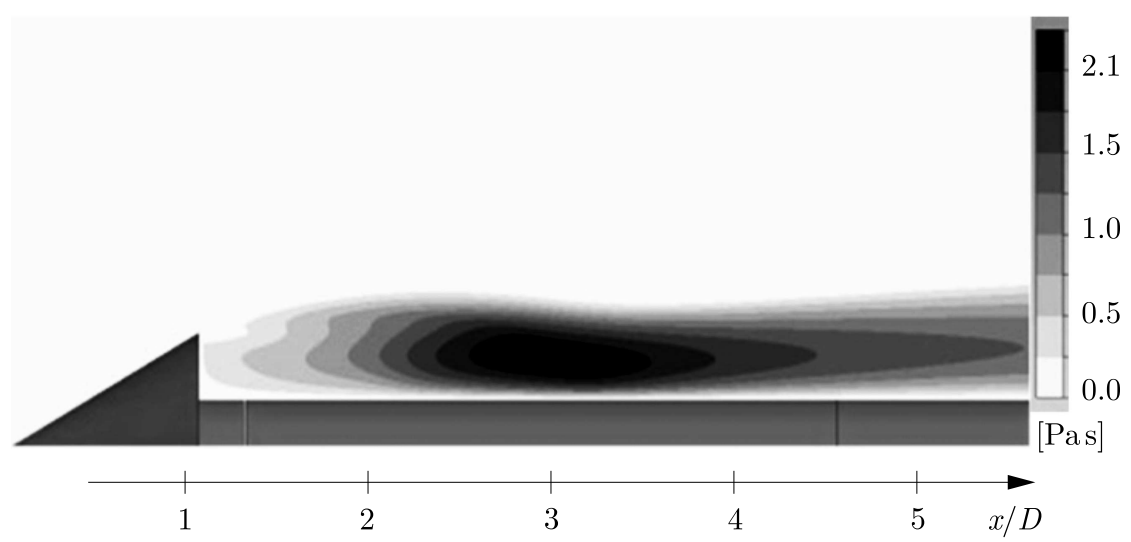

Fig. 16. Turbulent eddy viscosity contours around the $45^{\circ}$ cone cavitator

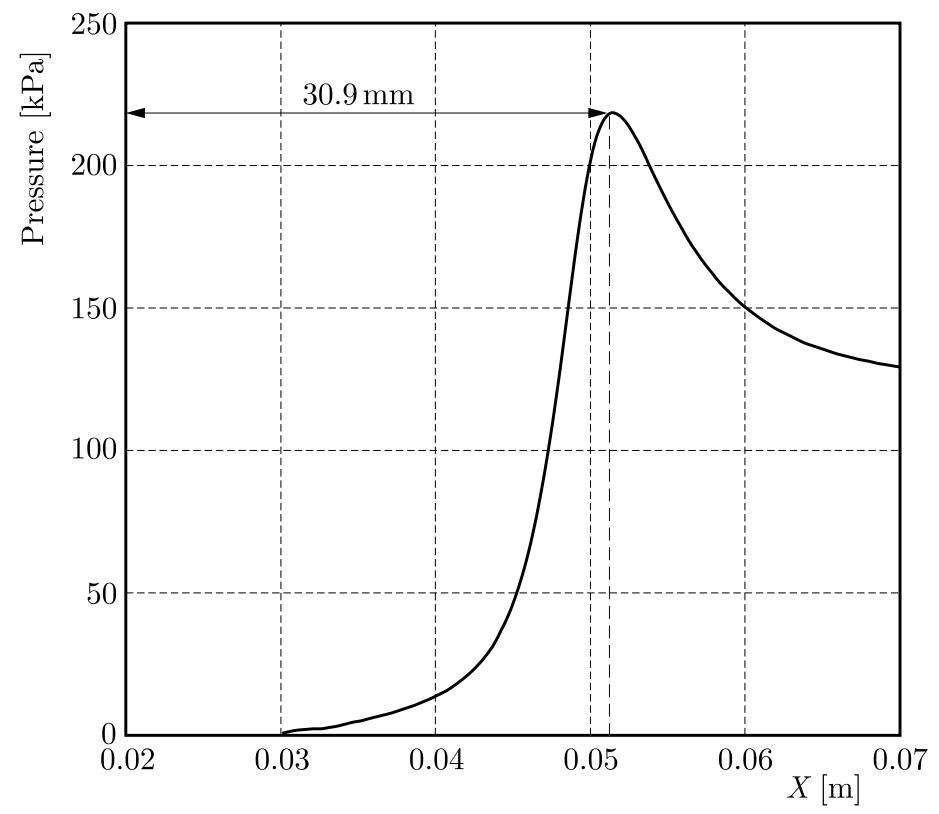

Fig. 17. Cavity length of the $30^{\circ}$ cone cavitatorat $v=32 \mathrm{~m} / \mathrm{s}$ 


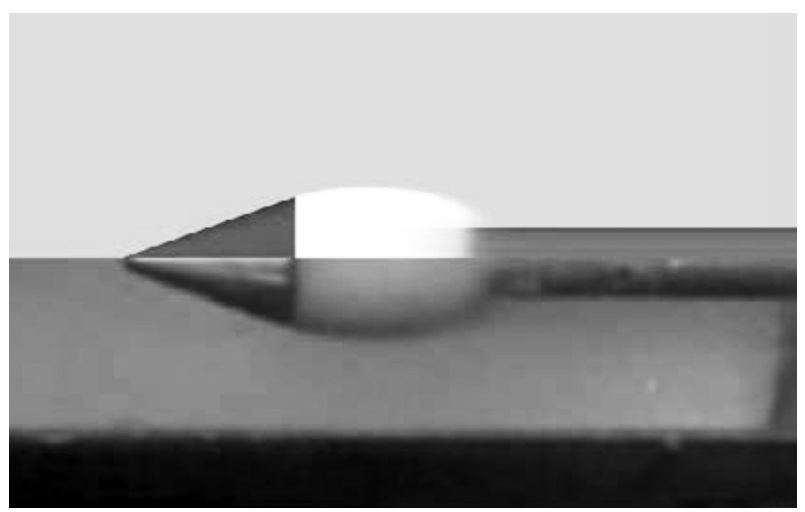

Fig. 18. The shape of the natural cavity from experiments and simulations at $v=28 \mathrm{~m} / \mathrm{s}$ for the $30^{\circ}$ conecavitator

(a)

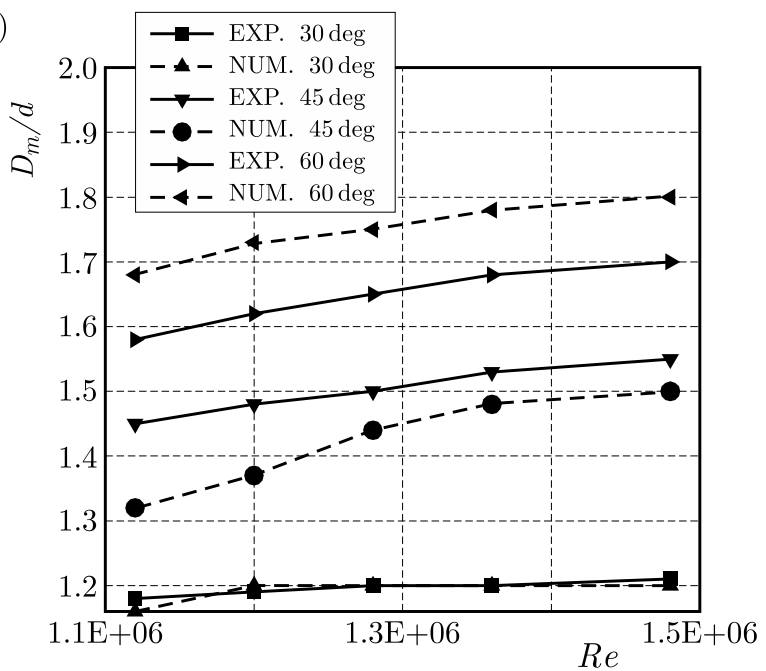

(b)

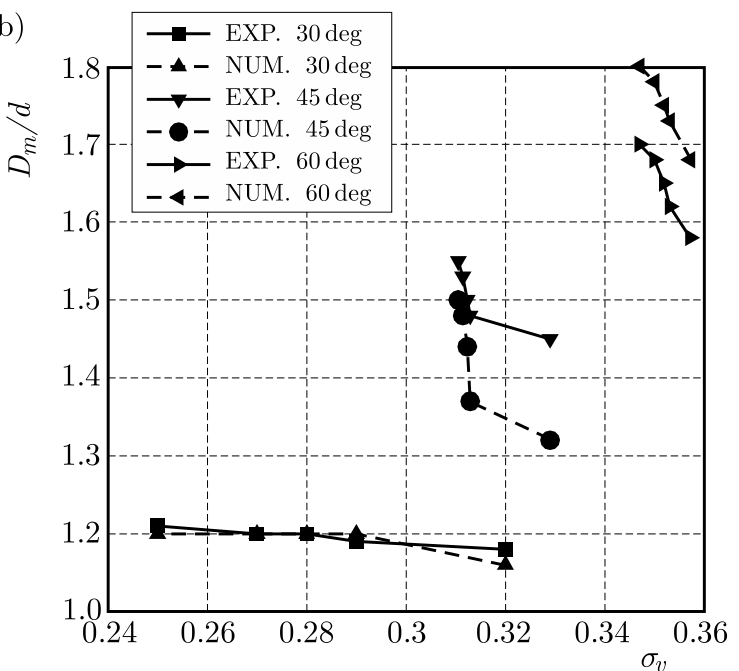

Fig. 19. Variation of the maximum cavity diameter (a) with the Reynolds number and (b) with the cavitation number for various types of cavitators

(a)

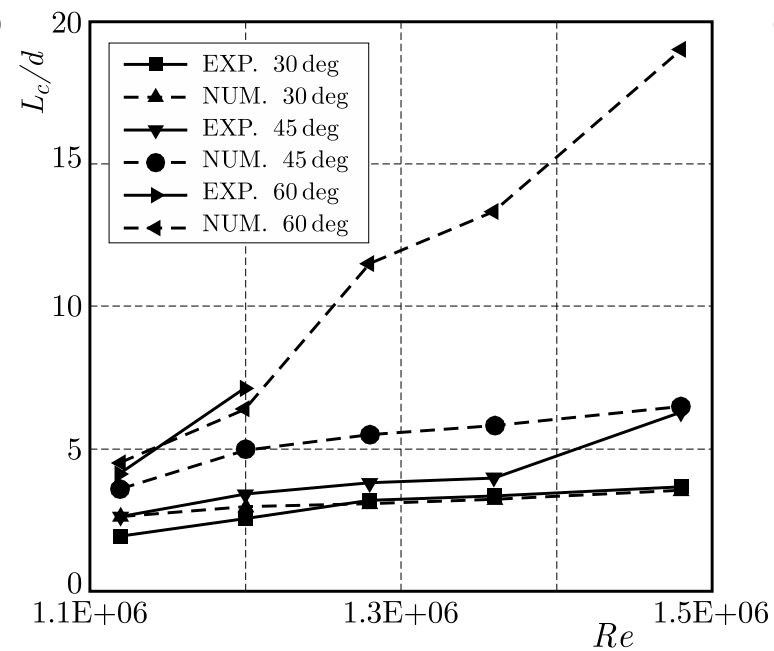

(b)

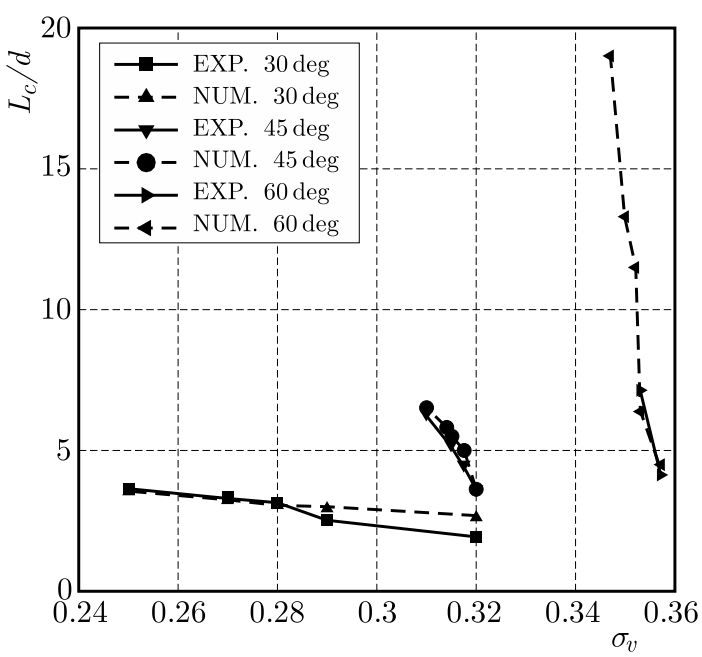

Fig. 20. Cavity lengths variation (a) with the Reynolds number and (b) with the cavitation number for various types of cavitator 
constant slope. The length of the supercavity increases exponentially when the cavitation number decreases (Fig. 20b). Also, by increasing the angle of the cavitator, the cavity length variation is augmented. The results indicate that the cavity length is associated with the cavitation number and flow velocity along with a number of other parameters like geometry of the cavitator. Note that the cavitator length for higher angles rises significantly with an increase in the Reynolds number. A comparison of the numerical and experimental results confirms the acceptable level of accuracy.

\section{Conclusion}

In this paper, the cavitating flow around some cone cavitators is studied both numerically and experimentally. The experimental tests are carried out in a semi-open loop water tunnel. The effects of the cone angle of cavitators, magnitude of the free stream velocity and the cavitation number on the shape of the formed cavity and their drag coefficients are investigated.

To sum up, the following conclusions can be drawn:

- A good agreement is found between the numerical and experimental results, indicating that the proposed method is capable of predicting the cavitating flow to calculate both the cavity shape and its length.

- The cavity length is directly proportional to the cone angle of the cavitator. Thus, a way to increase the cavity length is to increase the cone angles of the cavitators.

- The drag coefficient of bodies drops as the cavitation number decreases. The drag coefficient variation is similar to cavitation number variation. If the Reynolds number remains constant, a decrease in the cone angle of the cavitator reduces the drag coefficient down to approximately $40 \%$. Also, by increasing the cavitation number from 0.25 to 0.32 , the drag coefficient is increased by $28 \%$ for the cavitator of $30^{\circ}$ cone angle.

- The maximum diameter of the cavity shape and its length decrease as the cavitation number increases. For a cavitator with a $60^{\circ}$ cone angle, the reduction of the maximum diameter and length of the cavity is 1.2 and 6.3 times greater than in the $30^{\circ}$ cone cavitator respectively.

- For a free-stream velocity of $v=28 \mathrm{~m} / \mathrm{s}$, the difference of cavity length for the three cavitators is almost negligible $(2.2 \mathrm{~cm})$, but with an increase in the flow velocity, the displacement of cavity length for the three cavitators is increased. The cavity diameter is reduced as the flow velocity declines at a constant rate for the three cavitators. Also, by increasing the Reynolds number from $112 \cdot 10^{4}$ to $148 \cdot 10^{4}$, the cavity length increases by about 95 to $375 \%$ for the $60^{\circ}$ cone cavitator.

\section{References}

1. Ahn B., Ahn C., Lee C., Kim T., 2010, Experimental and numerical studies on supercavitating flow of axisymmetric cavitators, International Journal of Naval Architecture and Ocean Engineering, 2, 39-44

2. Athavale M.M, Li H.Y., Jiang Y., Singal A.K., 2002, Application of the full cavitation model to pumps and Inducers, International Journal of Rotating Machinery, 8, 45-56

3. Chen Y., Lu C.-J., 2008, A homogenous-equilibrium model based numerical code for cavitation flows and evaluation by computation cases, Journal of Hydrodynamics, 20, 2, 186-194

4. Chen Y., Lu C.-J., Wu L., 2006, Modelling and computation of unsteady turbulent cavitation flow, Journal of Hydrodynamics, Ser. B, 18, 5, 559-566 
5. Choi J.Y., Ruzzene M., 2006. Stability analysis of supercavitating underwater vehicles with adaptive cavitator, International Journal of Mechanical Sciences, 48, 1360-1370

6. Deng F., Zhang Y., Chen W., Yuan X., Dang J., 2004, Experimental investigation on the incipiency and the shape of supercavity for slender bodies with different headforms, Journal of Northwestern Polytechnical University, 22, 3, 269273

7. Fong X.-M., Lu C.-J., Hu T.-Q., 2002, Experimental research on a supercavitating slender body of revolution with ventilation, Journal of Hydrodynamics, Ser. B, 2, 17-23

8. Franc J.P., Michel J.M., 2004, Fundamentals of Cavitation, Section 6, Kluwer Academic Publisher, Netherlands

9. Hrubes J.D., 2001, High-speed imaging of supercavitating underwater projectiles, Experiments in Fluids, 30, 57-64

10. Huang B., Wang G., 2011, Partially averaged Navier-Stokes method for time-dependent turbulent cavitating flows, Journal of Hydrodynamics, 23, 1, 26-33

11. Huang S., He M., Wang C., Chang X., 2010, Simulation of cavitating flow around a 2-D hydrofoil, Journal of Marine Science and Application, 9, 63-68

12. Hu X., Gao Y., 2010, Investigation of the disk cavitator cavitating flow characteristics under relatively high cavitation number, Applied Mechanics and Materials, 29-32, 2555-2562

13. Huuva T., 2008, Large eddy simulation of cavitating and non-cavitating flow, PhD thesis, Chalmers University of Technology, Sweden

14. Ji B., Luo X., 2010, Numerical investigation of the ventilated cavitating flow around an underwater wehicle based on a three-component caviation model, Journal of Hydrodynamics, 22, 6, 753-759

15. Kuklinski R., Henoch C., Castano J., 2001, Experimental study of ventilated cavities on dynamic test model, 4th International Symposium on Cavitation, California, USA

16. Kunz R.F., Boger D.A., Chyczewski T.S., Stinebring D.R., Gibeling H.J., Govindan T.R., 1999. Multi-phase CFD analysis of natural and ventilated cavitation about submerged bodies, ASME Paper FEDSM, 99-7364

17. Launder B.E., Spalding D.B., 1972, Lectures in Mathematical Models of Turbulence, Academic Press, London, UK

18. LeE Q.-T., XUE L.-P., HE Y.-S., 2008, Experimental study of ventilated supercavities with a dynamic pitching model, Journal of Hydrodynamics, 20, 4, 456-460

19. Li X., Wang G., Zhang M., Shyy W., 2008, Structures of supercavitating multiphase flows, Journal Thermal Science, 47, 1263-1275

20. Lin H., Lin Q., Hu T., 2004, An experimental study on fluctuating hydrodynamic loads on cavitating axisymmetric slender bodies, Journal of Hydrodynamics, Ser. A, 19, 6, 794-800

21. Lindau J.W., Kunz R.F., Boger D.A., Stinebring D.R., Gibeling H.J., 2002, High Reynolds number, unsteady, multiphase CFD modeling of cavitating flows, Journal of Fluids Engineering, Transactions of ASME, 124,3,607-616

22. Liu D., Hong F., Lu F., 2010, The numerical and experimental research on unsteady cloud cavitating flow of 3D elliptical hydrofoil, Journal of Hydrodynamics, 22, 5, 759-763

23. LiU D., LiU S., Wu Y., XU H., 2009, LES numerical simulation of cavitation bubble shedding on ALE 25 and ALE 15 hydrofoils, Journal of Hydrodynamics, 21, 6, 807-813

24. Logvinovich G.V., 1969, Hydrodynamics of Flows with Free Boundaries, Kiev, USSR, Naukova Dumka

25. Logvinovich G.V., 1980, Some problems in planing surfaces (in Russian), Trudy Tsagi, 2052, Moscow, Russia, Central Aero and Hydrodynamics Institute 
26. Lu N., Bensow R.E., BARK G., 2010, LES of unsteady cavitation on the delft twisted foil, Journal of Hydrodynamics, Ser. B, 22, 5, 784-791

27. Merkle C.L., Feng J., Buelow P.E.O., 1998, Computational modeling of the dynamics of sheet cavitation, Proceeding of the 3rd International Symposium on Cavitation (CAV98), Grenoble, France

28. Nouri N.M., Shienejad A., Eslamdoost A., 2008, Multi phase computational fluid dynamics modeling of cavitating flows over axisymmetric head-forms, IUST International Journal of Engineering Science, 19, 1/5, 71-81

29. PArk S., Rhee S.H., 2012, Computational analysis of turbulent supercavitating flow around a twodimensional wedge-shaped cavitator geometry, Computers and Fluids, 70, 73-85

30. Phoemsapthawee S., Leroux J., Kerampran S., Laurens J., 2012, Implementation of a transpiration velocity based cavitation model within a RANS solver, European Journal of Mechanics B/Fluids, 32, 45-51

31. Pouffary B., Fortes-Patella R., Reboud J.L., 2003, Numerical simulation of cavitating flow around a 2D hydrofoil: a barotropic approach, Fith International Symposium on Cavitation, Osaka, Japan

32. Saranjam B., 2013, Experimental and numerical investigation of an unsteady supercavitating moving body, Ocean Engineering, 59, 9-14

33. Schnerr G., SAuer J., 2001, Physical and numerical modeling of unsteady cavitation dynamics, 4th International Conference on Multiphase Flows, New Orleans, USA

34. Semenenko V.N., 2001, Dynamic processes of supercavitation and computer simulation, RTO AVT Lecture Series on Supercavitatingows at VKI

35. Singhal A.K., Athavale M.M., Li H., Jiang Y., 2002, Mathematical basis and validation of the full cavitation model, Journal of Fluids Enginnering, 124, 617-624

36. VAsin A.D., PAryshev E.V., 2001, Immersion of a cylinder in a fluid through a cylindrical free surface, Journal of Fluid Dynamics, 36, 2, 168-177

37. Wang G., Ostoja-Starzewski M., 2007, Large eddy simulation of a sheet/cloud cavitation on a NACA 0015 hydrofoil, Applied Mathematical Modelling, 31, 3, 417-447

38. Wang H., Zhang J., Wei Y., Yu K., Jia L., 2005, Study on relations between cavity form and typical cavitator parameters, Journal of Hydrodynamics, Ser. A, 20, 2, 251-257

39. Wu J., Wang G., Shyy W., 2005, Time-dependent turbulent cavitating flow computation with interfacial transport and filter-based models, International Journal for Numerical Methods in Flu$i d s, 49,739-746$

40. Wu X., Chahine G.L., 2007, Characterization of the content of the cavity behind a high-speed supercavitating body, Journal of Fluids Enginnering, 45, 129-136

41. Zhang X.-W., Wei Y.-J., Zhang J.-Z., Chen Y., Yu K.-P., 2007, Experimental research on the shape characters of natural and ventilated supercavitation, Journal of Hydrodynamics, Ser. B, 19, 5, 564-571

42. Zou W., Yu K., WAN X., 2010, Research on the gas-leakage rate of unsteady ventilated supercavity, Journal of Hydrodynamics, 22, 5, 778-783 